Research Article

\title{
Mechanical Modeling of Roof Fracture Instability Mechanism and Its Control in Top-Coal Caving Mining under Thin Topsoil of Shallow Coal Seam
}

\author{
Peilin Gong, ${ }^{1}$ Tong Zhao ${ }^{(D},{ }^{2}$ Kaan Yetilmezsoy, ${ }^{3}$ and Kang $\mathrm{Yi}^{4}$ \\ ${ }^{1}$ College of Mining Technology, Taiyuan University of Technology, Taiyuan, Shanxi Province 030024, China \\ ${ }^{2}$ Key Laboratory of In Situ Modified Mining Ministry of Education, Taiyuan University of Technology, Taiyuan, \\ Shanxi Province 030024, China \\ ${ }^{3}$ Department of Environmental Engineering, Faculty of Civil Engineering, Yildiz Technical University, Davutpasa Campus, \\ Esenler, Istanbul 34220, Turkey \\ ${ }^{4}$ School of Energy and Mining Engineering, China University of Mining \& Technology, Beijing, Beijing City 100083, China \\ Correspondence should be addressed to Tong Zhao; zhaotong3501@126.com
}

Received 26 May 2019; Revised 13 July 2019; Accepted 30 August 2019; Published 27 October 2019

Academic Editor: Salvatore Grasso

Copyright (C) 2019 Peilin Gong et al. This is an open access article distributed under the Creative Commons Attribution License, which permits unrestricted use, distribution, and reproduction in any medium, provided the original work is properly cited.

\begin{abstract}
This study aimed to explore the safe and efficient top-coal caving mining under thin topsoil of shallow coal seam (SCS) and realize the optimization of hydraulic support. Numerical simulation and theoretical analysis were used to reveal the stress distribution of the topsoil, the structure characteristics of the main roof blocks, and the development of the roof subsidence convergence. Step subsidence of the initial fractured main roof after sliding destabilization frequently existed, which seriously threatened the safety of the hydraulic supports. Hence, a mechanical model of the main roof blocks, where the topsoil thickness was less than the minimum height of the unloading arch, was established, and the mechanical criterion of the stability was achieved. The working resistance of the hydraulic support was calculated, and the reasonable type was optimized so as to avoid crushing accident. Findings of the present analysis indicated that the hydraulic support optimization was mainly affected by fractured main roof blocks during the first weighting. According to the block stability mechanical model based on Mohr-Coulomb criterion, the required working resistance and the supporting intensity were determined as $4899 \mathrm{kN}$ and $0.58 \mathrm{MPa}$, respectively. The ZZF5200/ 19/32S low-position top-coal caving hydraulic support was selected for the studied mine and support-surrounding rock stability control of thin-topsoil SCS could be achieved without crushing accident.
\end{abstract}

\section{Introduction}

China has a large number of shallow coal seams, which have the characteristics of shallow buried depth, thin bedrock, and thick topsoil [1]. However, relatively thin topsoil commonly occurs in the shallow coal seam (SCS) mining areas such as Lu'an and Yongcheng. The thickness of topsoil with the minimum ratio of rock and loading in Niushan Coal Mine is only $30 \mathrm{~m}$, which is less than the minimum height of the unloading arch, failing to form the structures of "voussoir beam" or "stress arch" [2,3]. Because of the special ground control, the roof cutting and support crushing accidents happen easily in the mining $[4,5]$, which poses a serious threat to the production.

The clarification of the structural form, components, and mechanical characteristics of the overlying strata during coal extraction under different geological conditions is the core of ground pressure and strata control [6-9]. Abundant relevant studies on the typical SCS with thick topsoil have been conducted, and valuable results, theories of strata behavior, instability mechanism, and overburden migration, and structures of "voussoir beam" and "stress arch" have been obtained $[10,11]$. However, they fail to adequately explain the instability mechanisms of a thin-topsoil SCS, which is 
generally considered to be a special type for the obvious roof behavior discrepancy. The instability of the single key stratum structure usually causes roof step-form subsidence and sliding under the shallow coalfield longwall mining. With thin-topsoil SCS, sliding instability and the interaction and relationship between the roof behavior and the support resistance are mainly affected by the unloading effect of the topsoil. Nevertheless, to the best of the authors' knowledge, there are only a few studies on the thin-topsoil SCS mining [12-15], which meets new problems of unclear movement characteristics of the strata, the subjectivity of the support structure selection, and the inability to accurately determine the working resistance in the optimization of hydraulic support.

Considering the thin-topsoil SCS mining in Niushan Coal Mine as background and using the numerical simulation, theoretical analysis, and field measurement, the present study focused on the stress evolution, structural stability, and roof migration of the overlying strata under different supporting intensities. The study established the block stability mechanical model, revealed the instability mechanism of the roof fracture, and gave the formula for calculating the working resistance, determining the reasonable support type and control technology in the SCS working face of Niushan Coal Mine, where the topsoil thickness is less than the minimum height of the unloading arch.

\section{Materials and Methods}

2.1. Engineering Geological Conditions. Niushan Coal Mine (with latitude $35^{\circ} 43^{\prime} 09^{\prime \prime}-35^{\circ} 46^{\prime} 05^{\prime \prime}$ north, longitude $112^{\circ} 54^{\prime} 26^{\prime \prime}-112^{\circ} 56^{\prime} 20^{\prime \prime}$ east, and elevation $1026.5 \mathrm{~m}$ above sea level in Jincheng City, Shanxi Province, China) is located in the hilly area, and the production 3101 working face is in the northeast of the mine field (Figure 1). The 3\# coal seam, which is mainly mined, is $130-182 \mathrm{~m}$ deep. The fully mechanized top-coal caving method was adopted, and the ZF2200-16/24Z hydraulic support was used (Table 1). The supporting intensity was $0.4 \mathrm{MPa}$, and the support effect was good.

The succeeding 3102 working face is in the southwest of the mine field, whose strike length is $370 \mathrm{~m}$ and inclination length is $115 \mathrm{~m}$. As shown in Figure 2, the buried depth of coal seam is $35-83 \mathrm{~m}$, and it is about $35-51 \mathrm{~m}$ from the setup entry to the advancement of $230 \mathrm{~m}$. The topsoil thickness is $14.5-30.0 \mathrm{~m}$, and the bedrock is $9.3-21.7 \mathrm{~m}$. The coal thickness in the working face is $3.2-6.4 \mathrm{~m}$ with an average value of $4.8 \mathrm{~m}$, the inclination angle is $0-8^{\circ}$, and the coal seam hardness is $2-3$. The mining height is $2.0 \mathrm{~m}$, the caving height is $2.8 \mathrm{~m}$, the mining and caving ratio is $1: 1.4$, and the drawing interval is "one mining and one caving." Adopt "three-eight" system operation mode, two shifts production, and one shift maintenance. The ratio of rock and loading is defined as the thickness of the bedrock to that of the topsoil.

2.2. Roof Instability Characteristics Analysis through $\mathrm{Nu}$ merical Simulation. The thin-topsoil SCS working face was established by 3DEC numerical software (3-Dimension Distinct Element Code, produced by Itasca (Wuhan) Consulting Co., Ltd., Wuhan City, Hubei Province, China) $[16,17]$. The model size was the strike length $X=150 \mathrm{~m}$, inclination length $Y=1 \mathrm{~m}$, height $Z=65 \mathrm{~m}$. The area with the smallest ratio of rock and loading is the most dangerous area, which was mainly studied. The model adopted the discrete element blocks (called as block) to simulate the internal cracking and antiparticle friction of topsoil, which was divided by random joints [18]. Each block was divided into 3-6 deformation units (called as Zone), and the model was divided into 10659 discrete element blocks and 123466 deformation units.

The Mohr-Coulomb criterion was adopted in the calculation model, in which the bottom was fixed, the normal horizontal displacement was restricted in the lateral direction, and the top was the ground surface [19]. The physical and mechanical parameters of the model are shown in Table 2. The fish function was used for cycle coal cutting, support advancing, solution solving, and result saving. The surface force was applied to the roof-control area to simulate the support effect, and a total of $0.8 \mathrm{MPa}, 1.0 \mathrm{MPa}$, and 1.2 $\mathrm{MPa}$ supporting intensities were set to study the stress and displacement evolution of the stope during the first weighting and periodic weighting.

\section{Results and Discussion}

3.1. Stope Displacement Changes during the Weighting. Before the first weighting, as the working face was advanced, the roof sank obviously, and the subsidence convergence reached $156 \mathrm{~mm}$ when the supporting intensity was $0.6 \mathrm{MPa}$, as shown in Figure 3. When moved to $24 \mathrm{~m}$, the first weighting happened, and the subsidence convergence of the roof-control area reached $200 \mathrm{~mm}$ within a short time, resulting in a serious crushing accident.

When the supporting intensities were $0.8,1.2$, and 1.6 $\mathrm{MPa}$, the subsidence convergence in roof-control area reached the maximum during the first weighting, and the main roof periodically collapsed and sank with continuous advancement. The subsidence convergence during the first and second periodic weighting $(37 \mathrm{~m}-49 \mathrm{~m})$ was reduced to $50 \%-67 \%$ of that during the first weighting and became stable, and no crushing occurred.

Adjusting the supporting intensity of the thin-topsoil SCS working face can significantly change the roof-control effect, which meant the greater the supporting intensity, the smaller the subsidence convergence, and the higher security. Still the problem of the greater control cost existed, so it can comprehend security and support cost to determine the supporting intensity.

3.2. Stope Stress Evolution during the Weighting. The fracture migration rules and stope stress distribution under different supporting intensity (0.6 MPa, 0.8 MPa, and $1.2 \mathrm{MPa}$ ) were studied during both the first weighting and periodic weighting. The stope includes the coal wall directly in front of working face, immediate roof, main roof, and overlying 


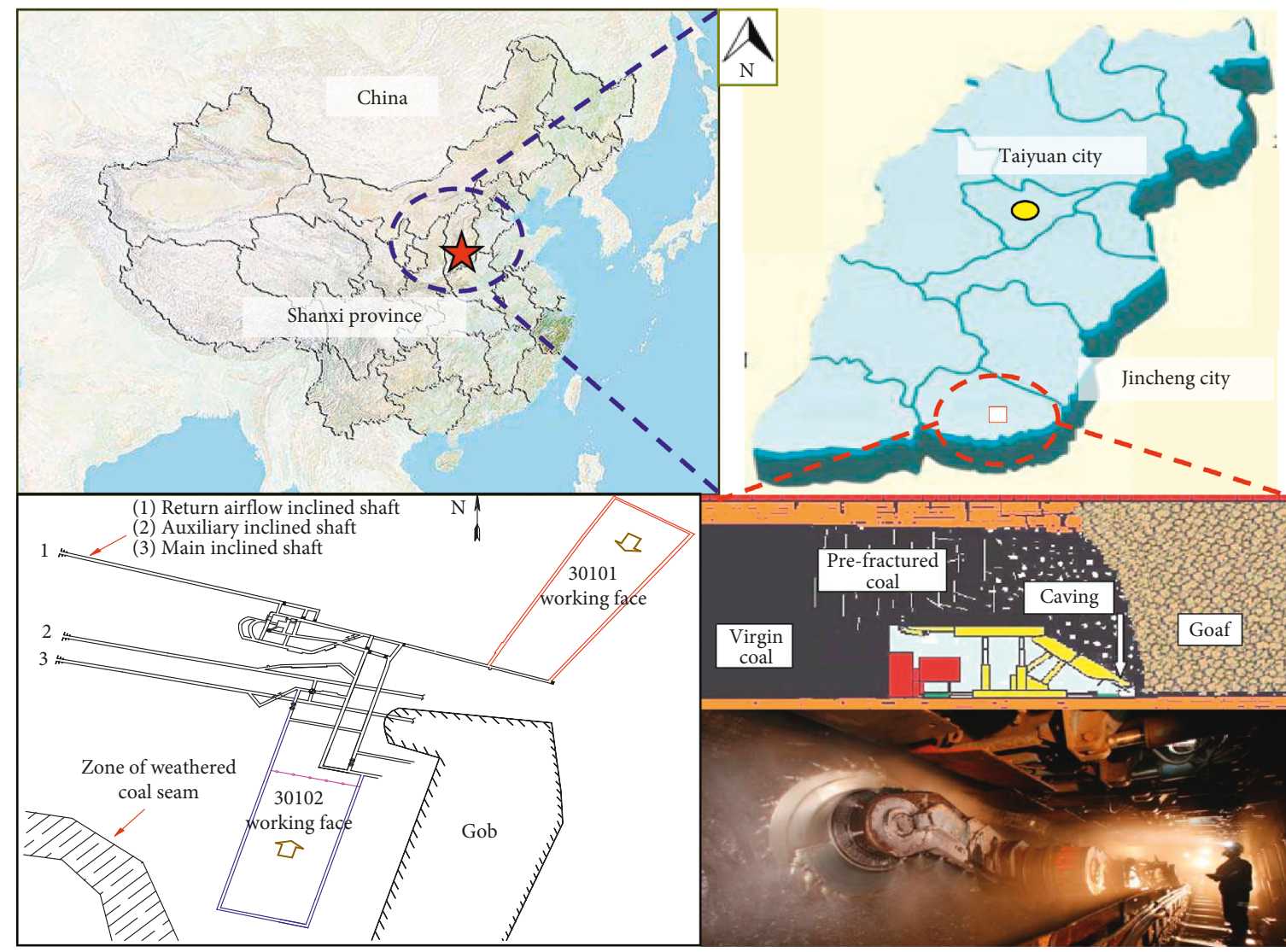

FIGURE 1: Map and satellite image showing the location of the studied mine and area.

TABLE 1: Hydraulic support used in 3101 working face.

\begin{tabular}{lc}
\hline Items & Parameters \\
\hline Mining height $(\mathrm{mm})$ & $1600-2400$ \\
Working resistance $(\mathrm{kN})$ & 2200 \\
Supporting area $\left(\mathrm{m}^{2}\right)$ & 5.75 \\
Adapt to coal seam dip $\left(^{\circ}\right)$ & $\leq 25^{\circ}$ \\
Supporting intensity $(\mathrm{MPa})$ & $0.51-0.56$ \\
Setting loading $(\mathrm{kN})$ & 1808 \\
Shift step $(\mathrm{mm})$ & 600 \\
Center distance $(\mathrm{mm})$ & 1250 \\
\hline
\end{tabular}

strata. The evolution and variation rules of stress can be obtained by comparing different stope stress distribution.

\subsubsection{Stope Stress Distribution during the First Weighting.} On the whole, the main roof was unstable when it was just fractured into independent blocks. With the step subsidence of the rock, the dynamic pressure was absorbed and the topsoil load was gradually discharged. When it was matched with the supporting intensity of the hydraulic support, a stable structure was formed, which is called the unloading effect, expressed by unloading coefficient. The unloading coefficient $\alpha$ is defined as the ratio of topsoil load after the main roof fractured to topsoil load before the main roof fractured, and during the first weighting, the unloading coefficient decreased first and then increased with the increase of support resistance.

\begin{tabular}{|c|c|c|c|c|}
\hline & Thickness (m) & Depth $(\mathrm{m})$ & Lithology & Remarks \\
\hline & 29.60 & 0 & Loess layer & \\
\hline & 6.93 & 29.60 & $\begin{array}{l}\text { Medium grain } \\
\text { sandstone }\end{array}$ & Main roof \\
\hline 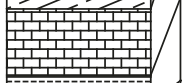 & 3.12 & 36.53 & Sandy mudstone & $\begin{array}{l}\text { Immediate } \\
\text { roof }\end{array}$ \\
\hline & 4.90 & 39.65 & Coal & \\
\hline 1 1 1 1 1 & 10.21 & 44.55 & Sandy mudstone & Floor \\
\hline
\end{tabular}

FIgURE 2: Stratigraphy of the coal rock bed.

In the simulation, when the working face moved to $24 \mathrm{~m}$, the tensile stress in the lower part of the main roof exceeded its ultimate tensile strength of $4.3 \mathrm{MPa}$, and the initial fracture occurred, completing the first weighting. The double-scale composite graph was adopted, the vertical compressive stress nephogram was selected for the topsoil, the cutting coal, and the floor, and the stress tensor graph for the caving coal, the immediate roof, and the main roof, as shown in Figure 4.

In Figure 4(a), when the supporting intensity was $0.6 \mathrm{MPa}$, the stress-relaxation area 1 appeared in the overburden layer of goaf, the topsoil load on the main roof was 
TABLE 2: Mechanical parameters of different rock blocks.

\begin{tabular}{|c|c|c|c|c|c|c|}
\hline Lithology & Thickness (m) & $\begin{array}{l}\text { Bulk modulus } \\
\left(K_{V}: \mathrm{GPa}\right)\end{array}$ & $\begin{array}{l}\text { Shear modulus } \\
(G: \mathrm{GPa})\end{array}$ & Tensile strength $(\mathrm{MPa})$ & $\begin{array}{l}\text { Cohesion } \\
(C: \mathrm{MPa})\end{array}$ & $\begin{array}{l}\text { Internal friction } \\
\text { angle }\left(j:{ }^{\circ}\right)\end{array}$ \\
\hline Loess layer & 30 & 0.10 & 0.08 & 0 & 0.05 & 20.0 \\
\hline Medium grain sandstone & 7 & 10.22 & 3.96 & 4.30 & 13.7 & 35.1 \\
\hline Sandy mudstone & 3 & 6.73 & 2.59 & 1.33 & 2.6 & 15.7 \\
\hline $3 \#$ coal & 5 & 3.21 & 9.65 & 0.72 & 1.27 & 17.8 \\
\hline Sandy mudstone & 20 & 8.95 & 3.66 & 2.71 & 7.57 & 19.6 \\
\hline
\end{tabular}

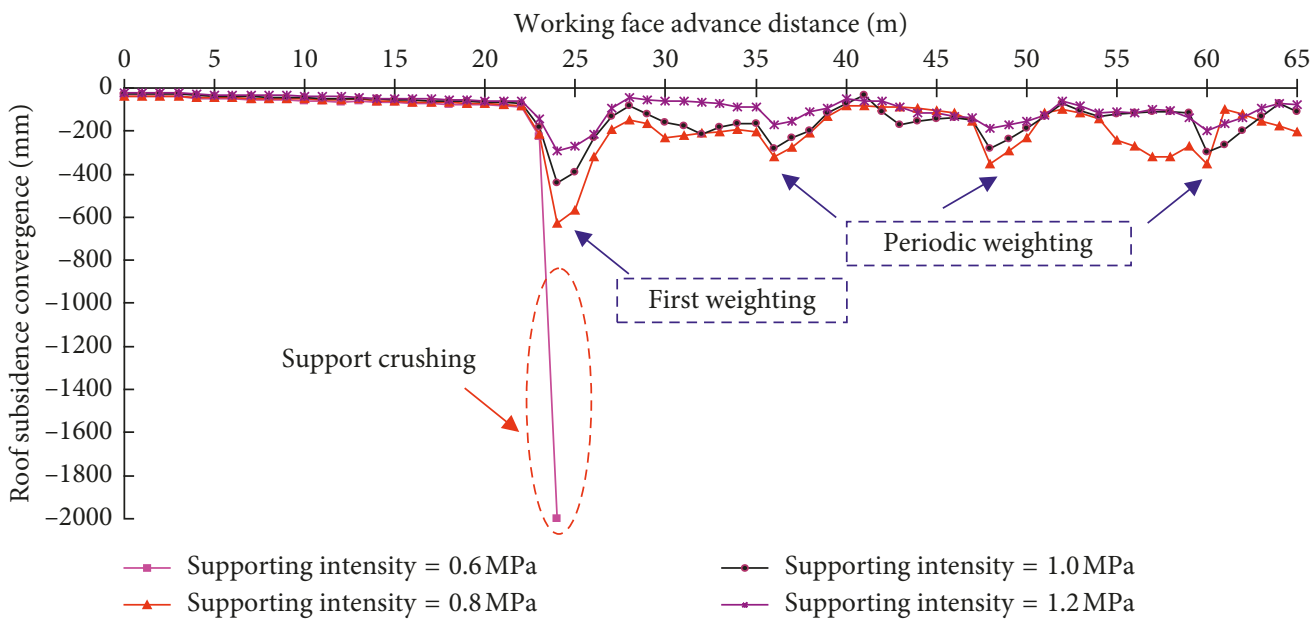

FIGURE 3: Variation of roof subsidence convergence with working face advanced distance.

reduced from $0.53 \mathrm{MPa}$ (before the fracture) to $0.46 \mathrm{MPa}$, and the unloading coefficient $\alpha=0.87$ at this time. The stress was transferred to the periphery to form the stress-concentration area 2, during which the topsoil load was increased from $0.53 \mathrm{MPa}$ to $0.76 \mathrm{MPa}$, and the stressconcentration factor was 1.43. It has been found that the load on the support was greater than the supporting intensity, which made it difficult to balance the pressure of the roof during mining. The roof step sank, and the subsidence convergence exceeded the minimum support height, which led to a crushing accident.

From Figures 4(b) and 4(c), when the supporting intensities were $0.8 \mathrm{MPa}$ and $1.2 \mathrm{MPa}$, the stress-relaxation area 1 appeared in the topsoil over the goaf, the topsoil loads on the main roof were reduced from $0.53 \mathrm{MPa}$ before the fracture to $0.18 \mathrm{MPa}$ and $0.25 \mathrm{MPa}$, and the unloading coefficients $\alpha$ were 0.34 and 0.47 , respectively. The topsoil load in the stress-concentration area 2 was increased from $0.53 \mathrm{MPa}$ to $0.73 \mathrm{MPa}$, and the stress-concentration factor reached 1.38, and the roof step subsidence convergences in the roof-control area were $0.63 \mathrm{~m}$ and $0.29 \mathrm{~m}$, respectively, and the hydraulic support and surrounding rock formed a stable structure during mining. This indicates that in the process of the initial fracture of the main roof to the formation of the hydraulic support-surrounding rock stable structure, the greater the supporting intensity, the smaller the subsidence convergence in the roof-control area, and the self-stabilizing structure was easy to be formed by the initial fractured rock, thus reducing the threat of step subsidence.
3.2.2. Stope Stress Distribution during the Periodic Weighting. For the safety of the hydraulic support, the stope stress evolution during the periodic weighting with the supporting intensity of $0.8 \mathrm{MPa}$ and $1.2 \mathrm{MPa}$ was analyzed, and a double-scale composite graph similar to Figure 1 was used, as shown in Figure 5. Figure 5 demonstrates that when the supporting intensities were $0.8 \mathrm{MPa}$ and $1.2 \mathrm{MPa}$, the loads on rock $\mathrm{C}$ were reduced from $0.53 \mathrm{MPa}$ to $0.32 \mathrm{MPa}$ and $0.46 \mathrm{MPa}$, respectively, and the unloading coefficient $\alpha$ was $0.60-0.87$. The stress-concentration area 4 was formed in front of the working face, inside, and behind the goaf, the topsoil load was increased to $0.86 \mathrm{MPa}$, and the stressconcentration factor was 1.62 .

The roof step subsidence convergence reached $0.35 \mathrm{~m}$ and $0.19 \mathrm{~m}$ when the supporting intensities were $0.8 \mathrm{MPa}$ and 1.2 $\mathrm{MPa}$, respectively. This was because the immediate roof of the shallow buried working face of Niushan Coal Mine was relatively thin $(3 \mathrm{~m})$ to fill the goaf, so the rock D sliced and fell to form "step beam" structure with the rotating rock $\mathrm{C}$.

In the present analysis, 2 topsoil thickness $(20 \mathrm{~m}$ and $40 \mathrm{~m})$ and 5 internal friction angles in topsoil $\left(10^{\circ}, 15^{\circ}, 20^{\circ}\right.$, $25^{\circ}$, and $30^{\circ}$ ) were chosen to establish 10 groups of numerical models [20]. Each group of numerical models was combined with 5 different support intensities randomly and considered to be excavated to the first weighting without crushing, obtaining $50 \alpha-H-\Delta S$ data sets ( $\alpha$ is the unloading coefficient; $H$ is the topsoil thickness ( $\mathrm{m})$; and $\Delta S$ is the step subsidence convergence $(\mathrm{m}))$. In Figure $6, \alpha$ was taken as the 


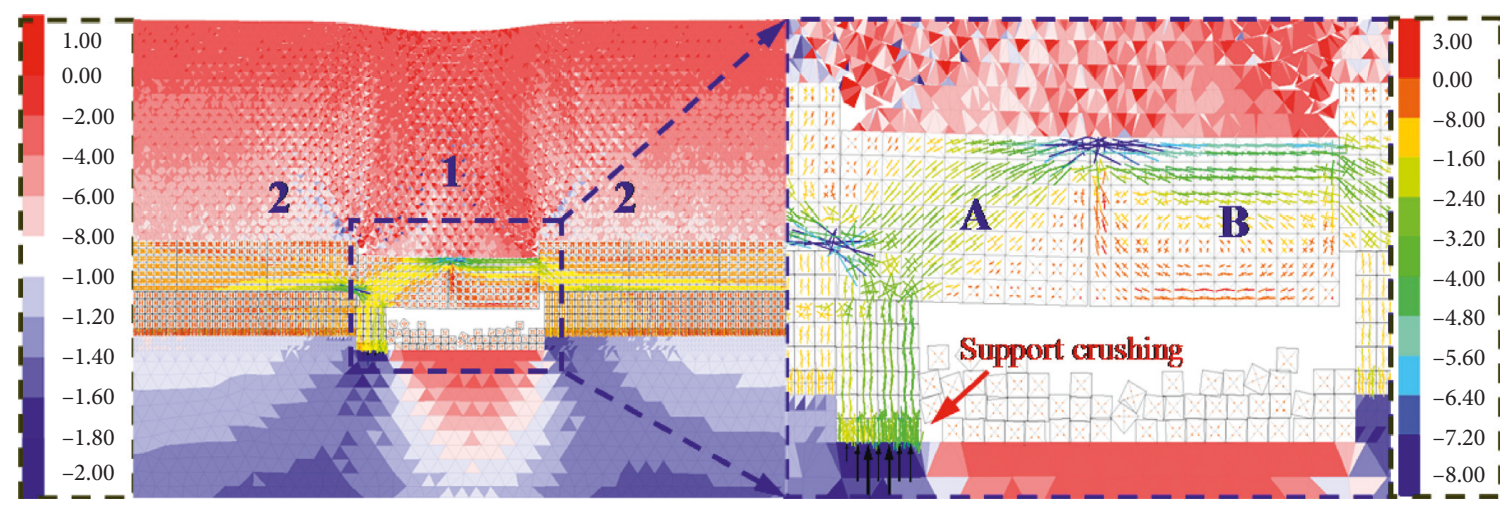

(a)

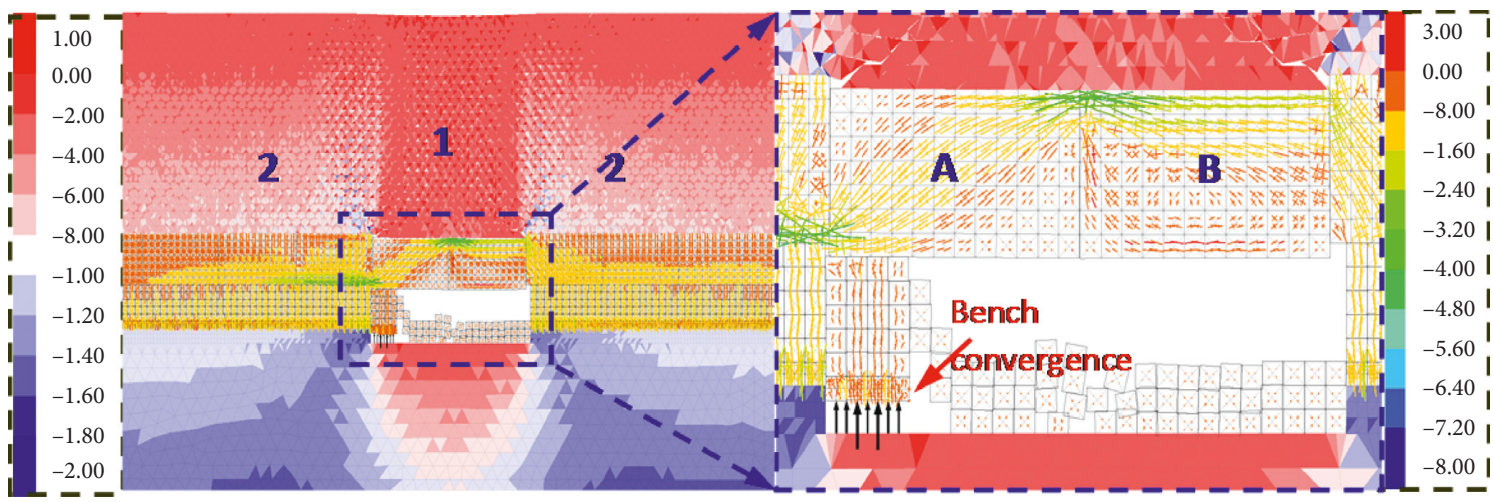

(b)

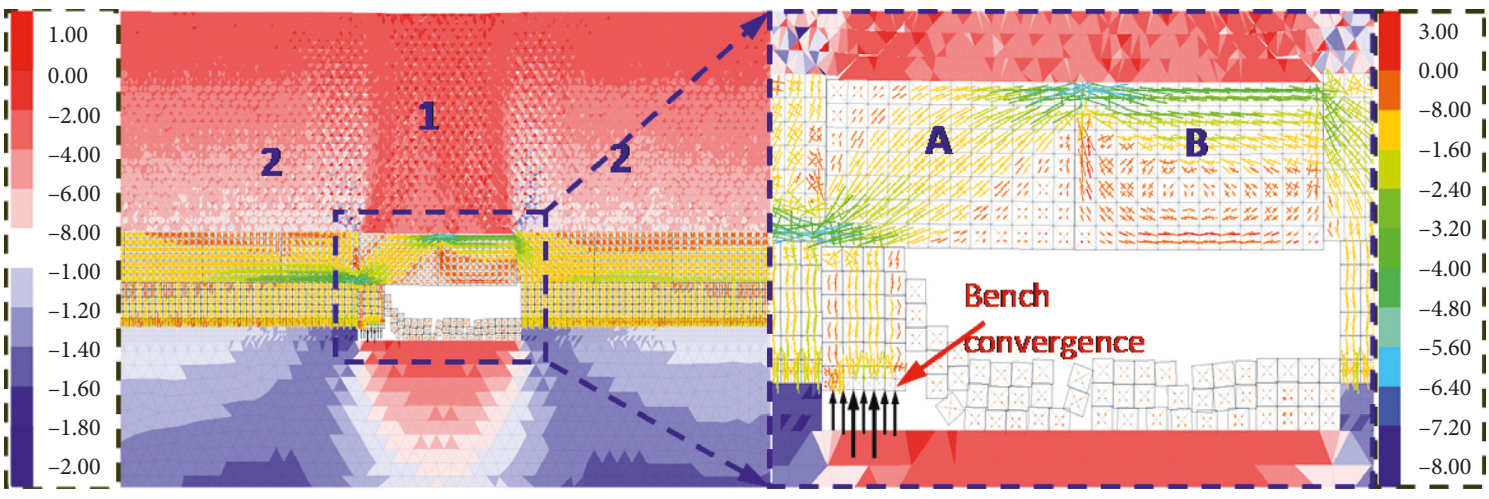

(c)

FIGURE 4: Stope stress distribution during the first weighting: (a) supporting intensity $0.6 \mathrm{MPa}$; (b) supporting intensity $0.8 \mathrm{MPa}$; (c) supporting intensity $1.2 \mathrm{MPa}$.

longitudinal axis, and $\Delta S$ as the horizontal axis, with red circle and black triangles to distinguish different $\mathrm{H}$ values. 50 data sets were drawn into the three-dimensional coordinate system and a multivariate nonlinear regression analysis was performed to obtain $\alpha$.

Results indicated that $\alpha=1-0.259 \ln (\Delta S+1) \sqrt{\tan (\phi)}$ showed a good fitness with only one unknown parameter. When 25 data sets with $H=20 \mathrm{~m}$ were fitted separately, $\alpha=0.261$, while when 25 data sets with $H=40 \mathrm{~m}$ were fitted separately, $\alpha=0.258$, which means $\alpha$ is not sensitive to $H$. In the present analysis, 50 data sets were combined to obtain the fitting surface of $\alpha$, as shown in Figure 6, from which unloading coefficient $\alpha$ during the first weighting can be determined according to the formula, $\alpha=1-0.259$ $\ln (\Delta S+1) \sqrt{\tan (\phi)}$.

The stope stress evolution process of the roof is shown in Figure 7. During weighting, the area with the largest principal stress in the topsoil was basically the same as the area with large shear stress. The maximum principal stress on both sides of the topsoil deviated from the goaf, and the dip angle was about $50^{\circ}$. This indicated that when the topsoil moved in the subsidence space, the topsoil load on the upper part of the main roof block was transferred to both sides. Meanwhile, the topsoil on both sides had an upward component force on the middle topsoil to transfer the load of the middle topsoil. 


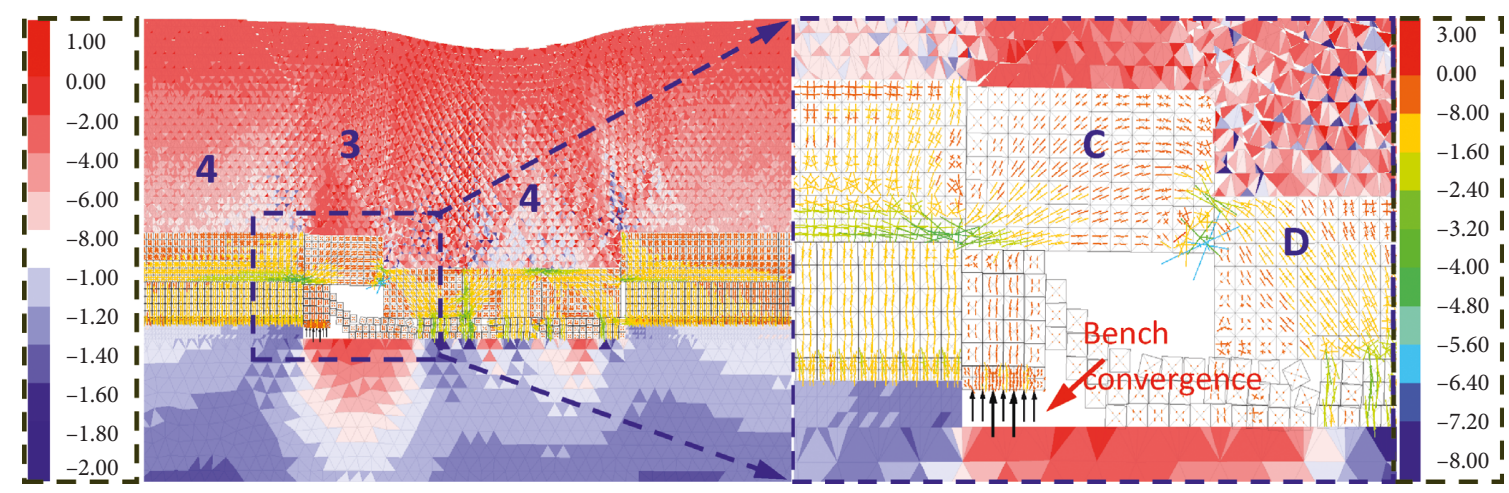

(a)

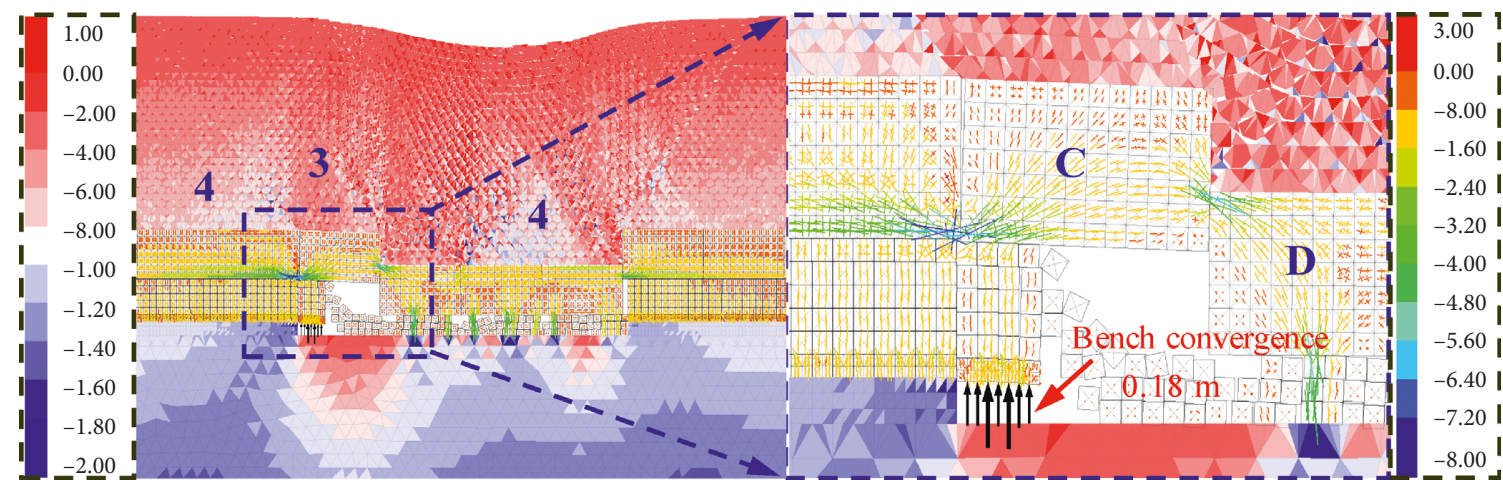

(b)

Figure 5: Stope stress distribution during the periodic weighting: (a) supporting intensity $0.8 \mathrm{MPa}$ and (b) supporting intensity $1.2 \mathrm{MPa}$.

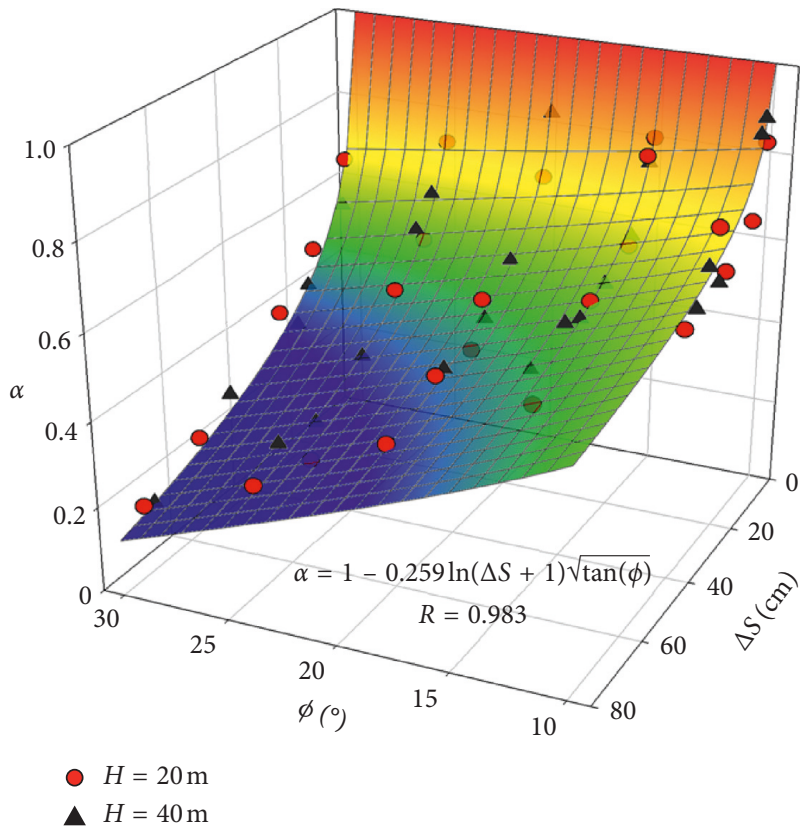

Figure 6: Fitting surface of unloading coefficient $\alpha$.

3.3. Working Resistance Calculation. Preventing crushing accidents caused by the main roof blocks sliding destabilization during the first weighting is the key to roofcontrol of the thin-topsoil SCS working face. Combined with the numerical simulation results, the roof force model of the first weighting was established, as shown in Figure 8. When the working face advanced to the first weighting interval, the main roof strata fractured into block $A$ and block B. Horizontal binding $T_{\mathrm{A}}$ and friction force $R_{\mathrm{A}}$, provided by rock mass on the side of working face, supporting force $P$, provided by the hydraulic support, and binding force, provided by block B, were supplied on block A. With working face continuing to advance, block A and block B collapsed and became instable. When the supporting intensity was less than the minimum value for block A to keep balance, step subsidence happened with significant vertical displacement on the side near the working face, whereas on the side of block $B$, because of small binding displacement provided by $\mathrm{B}$, unequal subsidence of block $\mathrm{A}$ appeared.

In Figure 8, $Q_{\mathrm{A}}$ and $Q_{\mathrm{B}}$ are the self-weight loads of block $\mathrm{A}$ and $\mathrm{B}$, respectively; $Q_{\mathrm{C}}$ is the self-weight load of top coal and immediate roof $(\mathrm{kN}) ; F_{1}$ is the combined force of topsoil load $(\mathrm{kN}) ; x_{1}$ is the horizontal distance from the point of topsoil load resultant force to point $O(\mathrm{~m}) ; R_{\mathrm{A}}$ and $R_{\mathrm{B}}$ are the frictional force of plastic hinges on block $A$ and $B$, respectively $(\mathrm{kN}) ; T_{\mathrm{A}}$ and $T_{\mathrm{B}}$ are the horizontal binding force of plastic hinges on block $A$ and $B$, respectively $(\mathrm{kN}) ; l_{0}$ is the first weighting interval $(\mathrm{m}) ; l$ is the length of rock block (about $\left.0.5 l_{0}\right)(\mathrm{m}) ; h$ is the thickness of main roof $(\mathrm{m}) ; h_{1}$ is the thickness of immediate roof $(\mathrm{m}) ; h_{2}$ is the thickness of top coal $(\mathrm{m}) ; l_{k}$ is the roof-control distance $(\mathrm{m})$; and $P$ is the working resistance of the unit width $(\mathrm{kN})$.

Taking $O$ as the midpoint for balance calculation, the following expressions are obtained: 


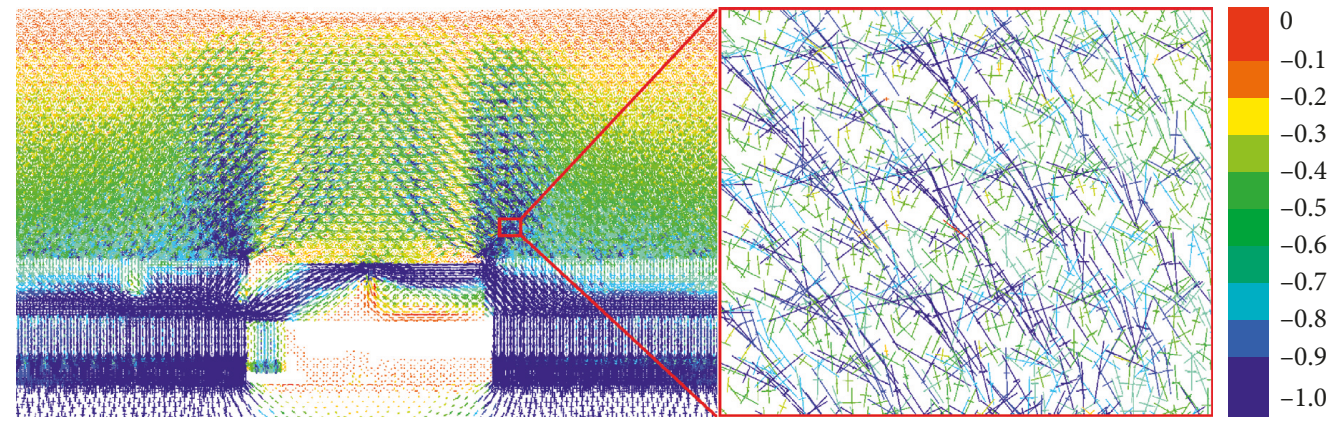

FIGURE 7: Surrounding rock stress tensors when main roof first weighting.

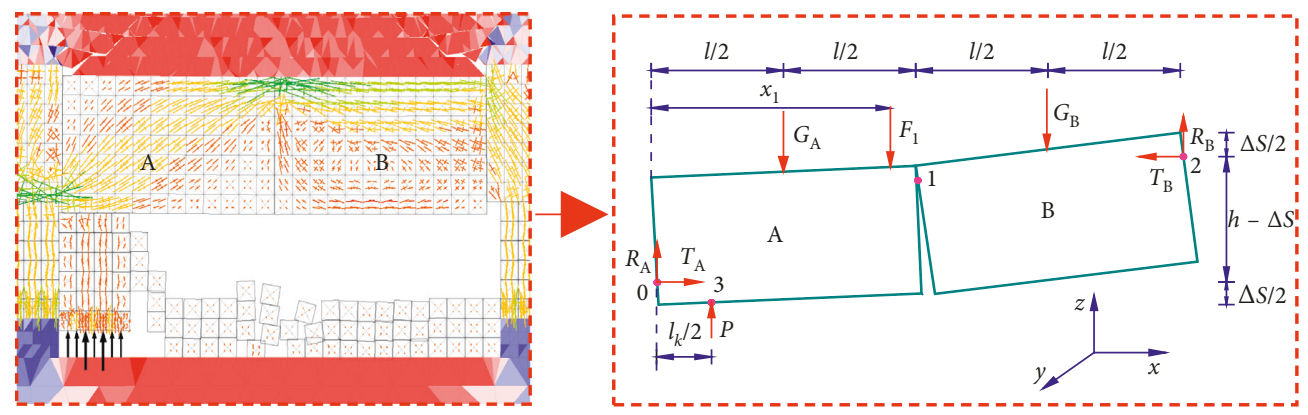

Figure 8: Force analysis of the fracture block.

$$
\begin{aligned}
\sum F_{x} & =0 \\
\sum F_{y} & =0 \\
\sum M_{0} & =0 \\
T_{\mathrm{A}} & =T_{\mathrm{B}}, \\
R_{\mathrm{A}}+R_{\mathrm{B}}+P & =Q_{\mathrm{A}}+Q_{\mathrm{B}}+Q_{\mathrm{C}}+F_{1}, \\
P \frac{l_{k}}{2}+R_{\mathrm{B}} 2 l+T_{B}(h-\Delta S) & =Q_{\mathrm{A}} \frac{l}{2}+Q_{\mathrm{B}} \frac{3 l}{2}+Q_{\mathrm{C}} \frac{l_{k}}{2}+F_{1} x_{1},
\end{aligned}
$$

where $F_{1}$ and $x_{1}$ are simplified by the measured point stress value $S_{i}$ and position $x_{i}$ read by the fish language. The interval $\mathrm{d} x=0.1 \mathrm{~m}$ and point number $n=239$.

The principle of simplifying the topsoil load is given by the following equation:

$$
\sum M_{0}=x_{1} F_{1}=\sum x_{i} S_{i} \mathrm{~d} x,
$$

where $x_{1}=\sum x_{i} S_{i} \mathrm{~d} x / \sum S_{i} \mathrm{~d} x$. From numerical simulation, $x_{1}=(0.933-0.976) l$ and the average is $0.961 l$.

The topsoil load $F_{1}$ on the block $A$ and $B$ is

$$
F_{1}=2 \alpha \gamma_{4} H l
$$

where $\alpha$ is the unloading coefficient of first weighting and $\gamma_{4}$ is the topsoil bulk density $\mathrm{kN} / \mathrm{m}^{3}$.

The self-weight load of top coal and immediate roof, block $\mathrm{A}$ and block $\mathrm{B}$ are

$$
\begin{aligned}
& Q_{C}=\left(\gamma_{1} h_{1}+\gamma_{2} h_{2}\right) l_{k}, \\
& Q_{A}=Q_{B}=\gamma_{3} h l,
\end{aligned}
$$

where $\gamma_{1}$ is the immediate roof bulk density $\left(\mathrm{kN} / \mathrm{m}^{3}\right) ; \gamma_{2}$ is the top coal bulk density $\left(\mathrm{kN} / \mathrm{m}^{3}\right)$; and $\gamma_{3}$ is the main roof bulk density $\left(\mathrm{kN} / \mathrm{m}^{3}\right)$.

When the structure slipped unstably, the two blocks sank at the same time, which indicated that both $R_{\mathrm{A}}$ and $R_{\mathrm{B}}$ reached the maximum friction force $(\mathrm{kN})$ with the limit equilibrium achieved, namely [21],

$$
\begin{aligned}
& R_{\mathrm{A}}=T_{\mathrm{A}} \tan \varphi ; \\
& R_{\mathrm{B}}=T_{\mathrm{B}} \tan \varphi .
\end{aligned}
$$

Based on the above analysis, the calculation formula of working resistance of the unit width when the thickness of the topsoil $H$ is less than the minimum height of the unloading arch:

$$
\begin{aligned}
P= & \frac{\alpha \gamma_{4} H l(0.078 l \tan \varphi+h-\Delta S)+\gamma_{3} h l(h-\Delta S)}{\tan \varphi\left(l-\left(l_{k} / 2\right)\right)+((h-\Delta S) / 2)} \\
& +\left(\gamma_{1} h_{1}+\gamma_{2} h_{2}\right) l_{k}, \\
\alpha= & 1-0.259 \ln (\Delta S+1) \sqrt{\tan (\phi)} ; \quad l=h \sqrt{\frac{R_{T}}{3 \gamma_{4} H / 1000}} .
\end{aligned}
$$

In equation (6), $\Delta S$ is the allowable step subsidence convergence $(\mathrm{m}), \varphi$ is the friction angle of main roof block $\left({ }^{\circ}\right), \phi$ is the friction angle in the topsoil $\left({ }^{\circ}\right), h_{1}$ is the thickness of immediate roof $(\mathrm{m}), h_{2}$ is the thickness of top coal $(\mathrm{m}), h$ is 


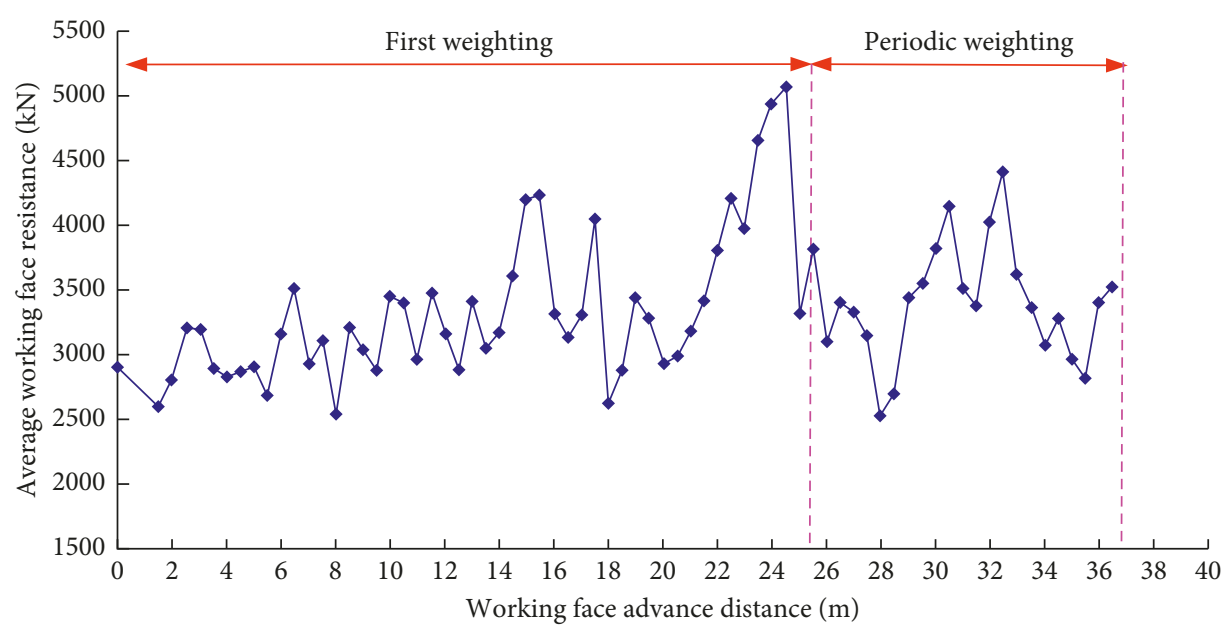

FIgURE 9: Measured average working resistance in the working face 3102.

the thickness of main roof $(\mathrm{m}), H$ is the thickness of topsoil (m), $L$ is the length of main roof rock block $(\mathrm{m})$, and $l_{k}$ is the roof-control distance $(\mathrm{m})$.

The values of the corresponding parameters of Niushan Coal Mine are as follows: $\phi=20^{\circ}, \gamma_{1}=23.4 \mathrm{kN} / \mathrm{m}^{3}, \gamma_{2}=$ $12.8 \mathrm{kN} / \mathrm{m}^{3}, \gamma_{3}=26.4 \mathrm{kN} / \mathrm{m}^{3}, \gamma_{4}=18.0 \mathrm{kN} / \mathrm{m}^{3}, h_{1}=3.12 \mathrm{~m}$, $h_{2}=2.90 \mathrm{~m}, h=6.93 \mathrm{~m}, H=29.6 \mathrm{~m}, R_{T}=4.3 \mathrm{MPa}, \varphi=35.1^{\circ}$, $l_{k}=4 \mathrm{~m}$, and $\Delta S=0.30 \mathrm{~m}$, thus the working resistance of unit support width is $P=3919 \mathrm{kN}$. When taking the original frame width $1.25 \mathrm{~m}$, the working resistance is $4899 \mathrm{kN}$ and the supporting intensity is $0.58 \mathrm{MPa}$.

Considering the geological conditions of thin-topsoil SCS working face of Niushan Coal Mine, the ZZF5200/19/ $32 \mathrm{~S}$ low-position top-coal caving hydraulic support was selected, with the maximum working resistance of $5200 \mathrm{kN}$, setting load of $4652 \mathrm{kN}$, center distance of $1500 \mathrm{~mm}$, minimum support height of $1.9 \mathrm{~m}$, maximum support height of $3.2 \mathrm{~m}$, and pumping station pressure of $31.5 \mathrm{MPa}$.

3.4. Assessment of Topsoil Characteristics. Compared with the thick bedrock condition, the mining under the thintopsoil SCS formed a single key stratum structure in the main roof [22-24], which would withstand the overburden load up to the land face. Before the main roof fractured, the topsoil load was approximately the gravity of the $H$-thickness topsoil. When the advanced length reached the first weighting interval, the main roof fractured under the topsoil load and its own gravity.

Because of the characteristics of the thin-topsoil SCS, the main roof failed to form a balanced structure, causing the step sinking followed by the downward movement of lowerintensity topsoil. The extrusion friction between the soil particles made the topsoil load on the main roof to transfer to both sides, which led to the reduction of the topsoil load, and the structure tended to be stable. As the step subsidence convergence of the main roof block increased, the extrusion friction between the soil particles increased gradually and the topsoil load decreased continuously. When the topsoil load reduced to a certain value, the support-surrounding rock could form a stable structure under the matched supporting intensity.

Therefore, topsoil load, topsoil friction characteristics, and the main roof step subsidence convergence may influence the unloading coefficient $[15,25]$. The topsoil load was mainly determined by the topsoil thickness, and the topsoil friction characteristics were mainly determined by the internal friction angle. The step subsidence convergence was related to the supporting intensity, which indicated that the main roof blocks would be easily balanced, and the step subsidence significantly reduced as the supporting intensity increased.

3.5. Field Application Effect Analysis. According to the field measurement (from November 20, 2017, to January 6, 2018) of the support load of the 3102 working face of Niushan Coal Mine, the average working resistance was calculated and is shown in Figure 9. Based on Figure 9, the average working resistance of the 3102 working face changed between 2600 and $5100 \mathrm{kN}$ during the whole mining stage. Combining the technical parameters and working characteristics of the central ZZF5200/19/32S hydraulic support, when the average rated working resistance reached $5200 \mathrm{kN}$ and the setting load was $4652 \mathrm{kN}$, the hydraulic support could meet the requirement. When the first weighting occurred, only 230-350 $\mathrm{mm}$ step subsidence appeared in the roof-control area, causing no crushing accident.

\section{Conclusions}

In this study, a block stability mechanical model within the framework of numerical simulation, theoretical analysis, and field measurement was established to study the safe and efficient top-coal caving mining under thin topsoil of SCS working face of a coal mine, where the topsoil thickness is less than the minimum height of the unloading arch. The stress distribution of the topsoil and structural stability of the main roof blocks were evaluated for determining the working resistance and optimizing the hydraulic support 
type under different supporting intensities. On the basis of the results obtained from the present numerical analysis, the following points can be drawn.

(1) As a special type, the thin-topsoil SCS mining presented particularity and new mechanism on its roof fracture and instability. The single key stratum had step subsidence after being broken, causing the topsoil load to gradually unload. When the load matched the supporting intensity, the hydraulic support crushing did not occur, and a stable supportsurrounding rock structure was formed.

(2) The mechanical model of the fractured main roof has been established, and the formula for calculating the working resistance when the topsoil thickness is less than the minimum height of unloading arch has been given. The required working resistance was $4899 \mathrm{kN}$, and the supporting intensity was $0.58 \mathrm{MPa}$.

(3) The ZZF5200/19/32S low-position top-coal caving hydraulic support has been selected, and the roof subsidence convergence reached 230-350 mm during the weighting stage, causing no crushing accident. The support-surrounding rock stability control of the thin-topsoil SCS during the mining has been achieved.

\section{Data Availability}

The data used to support the findings of this study are available from the corresponding author upon request.

\section{Conflicts of Interest}

The authors declare that there are no conflicts of interest including any financial, personal, or other relationships with other people or organizations.

\section{Acknowledgments}

This paper was supported by the China National Key R\&D Program during the 13th Five-Year Plan Period (no. 2017YFC0603003), Scientific and Technological Innovation Programs of Higher Education Institutions in Shanxi Province (STIP) (no. 2019L0347), and Natural Science Foundation of China (no. 51704204), which is greatly appreciated by the authors.

\section{References}

[1] C. Wang, C. Zhang, X. Zhao, L. Liao, and S. Zhang, "Dynamic structural evolution of overlying strata during shallow coal seam longwall mining," International Journal of Rock Mechanics and Mining Sciences, vol. 103, pp. 20-32, 2018.

[2] Z. Zhang, X. Yu, H. Wu, and M. Deng, "Stability control for gob-side entry retaining with supercritical retained entry width in thick coal seam longwall mining," Energies, vol. 12, no. 7, p. 1375, 2019.

[3] Q.X. Huang, "Study on roof control in shallow seam longwall mining," Chinese Journal of Rock Mechanics and Engineering, vol. 17, no. 5, pp. 521-526, 1998.
[4] Y. C. Li, "Prediction of the shear failure of opened rock fractures and implications for rock slope stability evaluation," Advances in Civil Engineering, vol. 2019, Article ID 6760756, 7 pages, 2019.

[5] T. Zhao, C. Y. Liu, K. Yetilmezsoy, B. S. Zhang, and S. Zhang, "Fractural structure of thick hard roof stratum using long beam theory and numerical modeling," Environmental Earth Sciences, vol. 76, no. 21, p. 751, 2017.

[6] Z. Li, J. Xu, S. Yu, J. Ju, and J. Xu, "Mechanism and prevention of a chock support failure in the longwall top-coal caving faces: a case study in Datong coalfield, China," Energies, vol. 11, no. 2, p. 288, 2018.

[7] B.-Y. Jiang, S.-T. Gu, L.-G. Wang, G.-C. Zhang, and W.-S. Li, "Strainburst process of marble in tunnel-excavation-induced stress path considering intermediate principal stress," Journal of Central South University, vol. 26, no. 4, pp. 984-999, 2019.

[8] D. M. Yang, W. B. Guo, and Y. Tan, "Study on the evolution characteristics of two-zone failure mode of the overburden strata under shallow buried thick seam mining," Advances in Civil Engineering, vol. 2019, Article ID 9874769, 9 pages, 2019.

[9] X.-F. Wang, Y. Wang, D.-S. Zhang et al., "Characteristics of strata behavior during thick seam mining by fully-mechanized top coal caving in a loess-covered gullied region," Minerals, vol. 7, no. 4, p. 63, 2017.

[10] P. Das and P. R. Mohanty, "Resistivity imaging technique to delineate shallow subsurface cavities associated with old coal working: a numerical study," Environmental Earth Sciences, vol. 75, no. 8, p. 661, 2016.

[11] J. Ju, J. Xu, and W. Zhu, "Longwall chock sudden closure incident below coal pillar of adjacent upper mined coal seam under shallow cover in the Shendong coalfield," International Journal of Rock Mechanics and Mining Sciences, vol. 77, pp. 192-201, 2015.

[12] P. Huang, A. J. S. Spearing, J. Feng, K. V. Jessu, and S. Guo, "Effects of solid backfilling on overburden strata movement in shallow depth longwall coal mines in west China," Journal of Geophysics and Engineering, vol. 15, no. 5, pp. 2194-2208, 2018.

[13] Z. J. Hou, "Study on key stratum in shallow seam," Journal of China Coal Society, vol. 24, no. 4, pp. 359-363, 1999.

[14] L. M. Dou, Z. L. Li, and X. Q. He, "Principle of rock burst control by weakening static and dynamic loading using topcoal caving in the mining of thick coal seams," Journal of China University of Mining \& Technology, vol. 47, no. 2, pp. 221-230, 2018.

[15] A. Kotyrba and K. Stańczyk, "Sensing underground coal gasification by ground penetrating radar," Acta Geophysica, vol. 65, no. 6, pp. 1185-1196, 2017.

[16] T. Zhao, C. Liu, K. Yetilmezsoy, P. Gong, and J. Li, "Realization and engineering application of hydraulic support optimization in residual coal remining," Journal of Intelligent \& Fuzzy Systems, vol. 32, no. 3, pp. 2207-2219, 2017.

[17] J.-H. Wu, W.-K. Lin, and H.-T. Hu, "Post-failure simulations of a large slope failure using 3DEC: the Hsien-du-shan slope," Engineering Geology, vol. 242, pp. 92-107, 2018.

[18] D. S. Yantek, L. Yan, N. W. Damiano, M. A. Reyes, and J. R. Srednicki, "A test method for evaluating the thermal environment of underground coal mine refuge alternatives," International Journal of Mining Science and Technology, vol. 29, no. 3, pp. 343-355, 2019.

[19] Q. Jiang, G. Su, X.-T. Feng, G. Chen, M.-Z. Zhang, and C. Liu, "Excavation optimization and stability analysis for large underground caverns under high geostress: a case study of the Chinese Laxiwa project," Rock Mechanics and Rock Engineering, vol. 52, no. 3, pp. 895-915, 2019. 
[20] M. G. Qian and P. W. Shi, Kuangshan Yali Yu Yanceng Kongzhi, China University of Mining and Technology Press, Xuzhou, China, 2010.

[21] Q. Jiang, F. Yan, J. Wu, Q. Fan, S. Li, and D. Xu, "Grading opening and shearing deformation of deep outward-dip shear belts inside high slope: a case study," Engineering Geology, vol. 250, pp. 113-129, 2019.

[22] Q. X. Huang, M. Y. Zhao, Y. L. Tan, and K. J. Huang, "Study of roof double key strata structure and support resistance of shallow coal seams group mining," Journal of China University of Mining \& Technology, vol. 48, no. 1, pp. 71-77, 2019.

[23] G. Zhu, X. Wu, S. Yu et al., "Surface water control for mining thick, relatively shallow coal seams in the loess area of western China," Mine Water and the Environment, vol. 37, no. 3, pp. 442-455, 2018.

[24] Y. Zhao, S. Wang, Z. Zou, L. Ge, and F. Cui, "Instability characteristics of the cracked roof rock beam under shallow mining conditions," International Journal of Mining Science and Technology, vol. 28, no. 3, pp. 437-444, 2018.

[25] F. L. He, Z. Zheng, H. Z. Zhu, and B. Yang, "Research on failure mechanism and strengthening of broken roadway affected by upper coal pillar," Advances in Civil Engineering, vol. 2019, Article ID 8132817, 13 pages, 2019. 


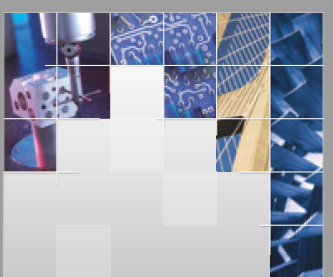

\section{Enfincering}
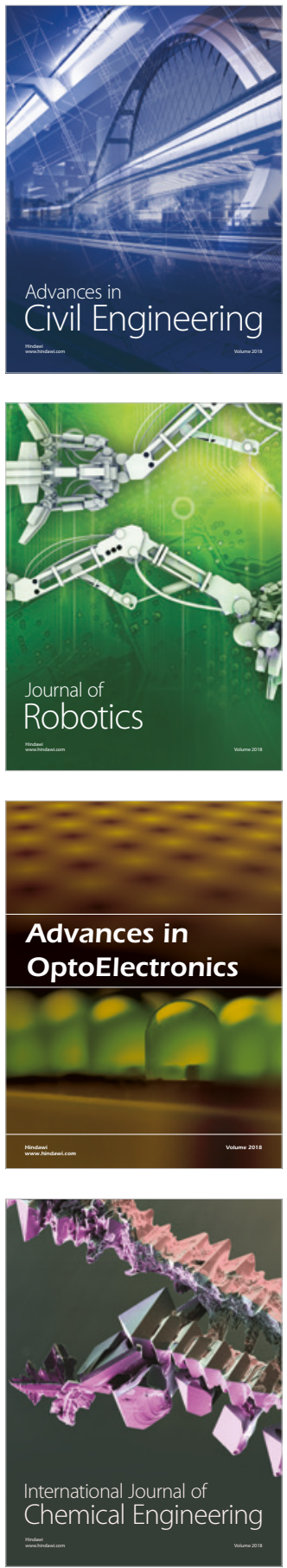

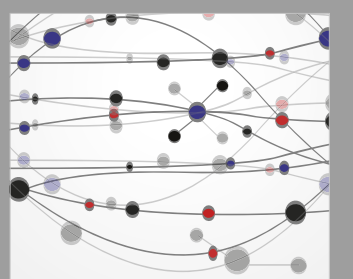

\section{Rotating \\ Machinery}

The Scientific World Journal

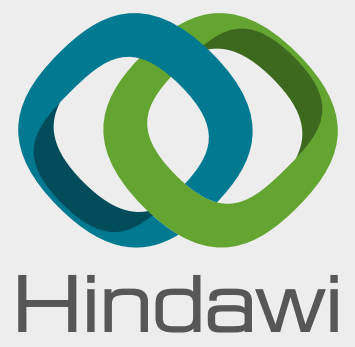

Submit your manuscripts at

www.hindawi.com
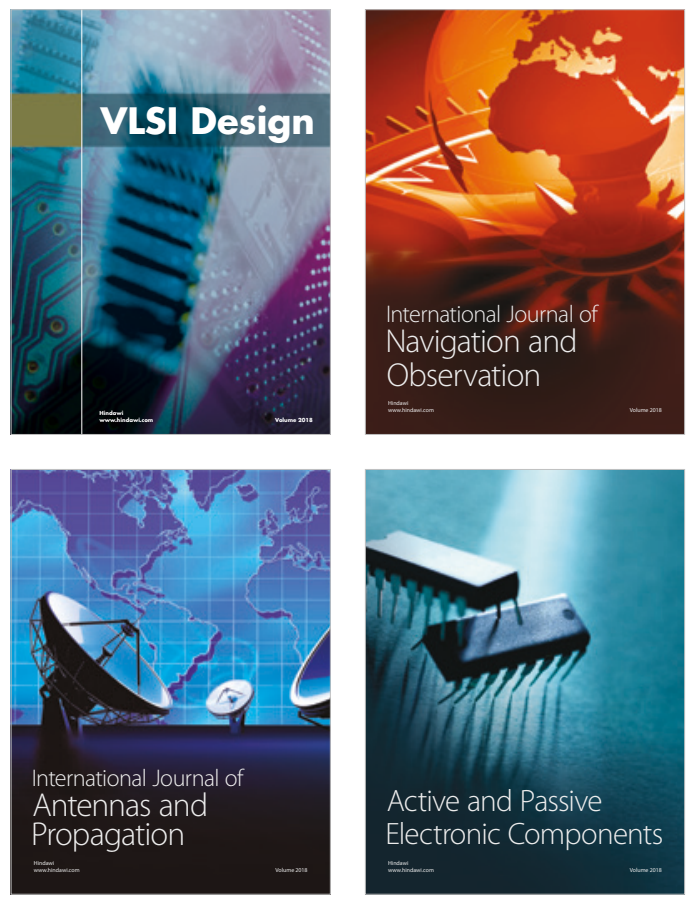
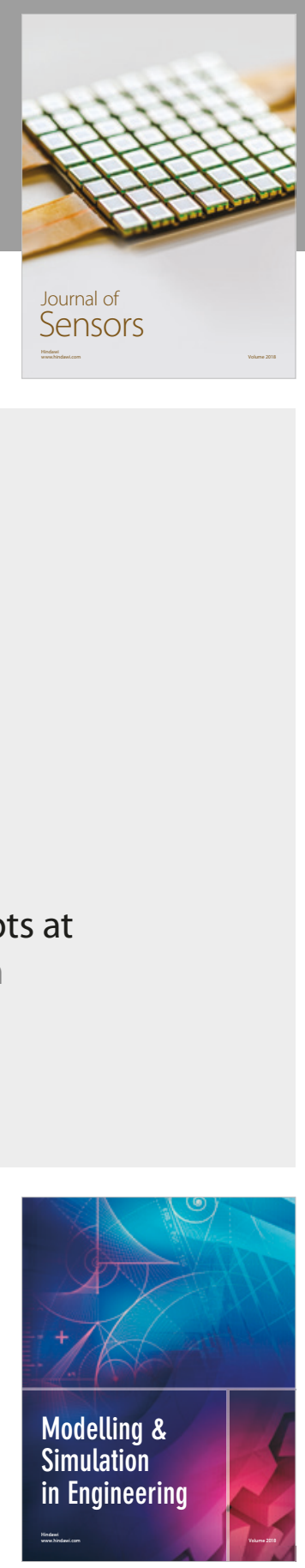

\section{Advances \\ Multimedia}
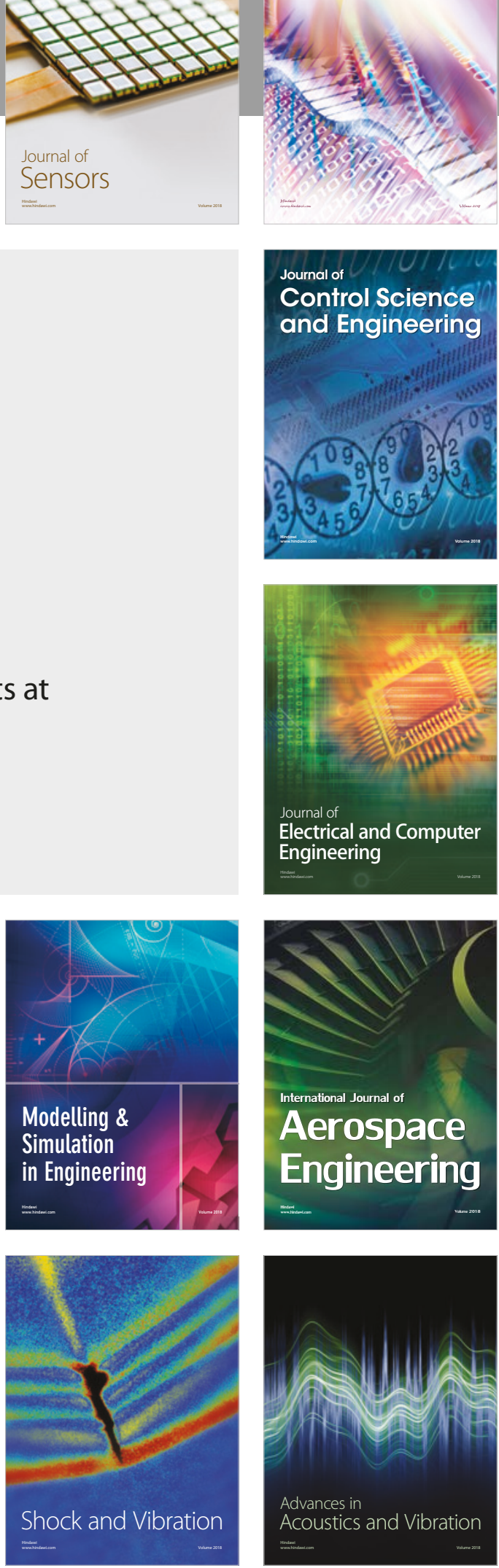